\title{
Determination of tar, nicotine, and carbon monoxide yields in the mainstream smoke of selected international cigarettes
}

\author{
A M Calafat, G M Polzin, J Saylor, P Richter, D L Ashley, C H Watson
}

Tobacco Control 2004;13:45-51. doi: 10.1136/tc.2003.003673

See end of article for authors' affiliations

......................

Correspondence to: Clifford $\mathrm{H}$ Watson, National Center for Environmental Health, Centers for Disease Control and Prevention, 4770 Buford Highway, $\mathrm{NE}$, Atlanta, GA 30341, USA; cowl@cdc.gov

Received 25 February 2003 Accepted 30 September 2003
Objective: Survey of nicotine, tar, and carbon monoxide (CO) smoke deliveries from 77 cigarette brands purchased in 35 countries was conducted using a standardised machine smoking method. The goal of this study was to determine regional variations and differences in the tar, nicotine, and CO smoke yields of a cigarette brand manufactured by a leading transnational corporation and of non-US locally popular cigarette brands.

Design: The majority of the cigarettes were purchased in each of the participating countries by delegate members of the World Health Organization and forwarded to the Centers for Disease Control and Prevention for analysis. Smoke deliveries were determined using a standardised smoking machine method and subsequent gravimetric and gas chromatography analysis.

Results: The smoke deliveries varied widely. Mainstream smoke deliveries varied from 6.8 to $21.6 \mathrm{mg}$ tar/ cigarette, 0.5 to $1.6 \mathrm{mg}$ nicotine/cigarette, and 5.9 to $17.4 \mathrm{mg} \mathrm{CO} /$ cigarette. In addition to the smoke deliveries, the cigarettes were examined to determine physical parameters such as filter composition, length, and ventilation levels.

Conclusion: Analysis of the smoke deliveries suggested that cigarettes from the Eastern Mediterranean, Southeast Asia, and Western Pacific WHO regions tended to have higher tar, nicotine, and CO smoke deliveries than did brands from the European, American, or African WHO regions surveyed.
$\mathrm{T}$ obacco related illnesses remain the leading cause of preventable death, with approximately 430000 annual deaths in the $\mathrm{USA}^{1}$ and approximately four million annual deaths worldwide attributed to tobacco use. ${ }^{2}$ Current projections suggest tobacco consumption threatens 10 million lives annually by 2030 , with $70 \%$ of these deaths projected in developing countries. ${ }^{3}$ Large transnational tobacco companies, such as Philip Morris (PM), Japan Tobacco, Inc., and BAT Industries (formerly British American Tobacco Company), have been increasing their presence in developed and developing countries through marketing and other financial activities such as event sponsorship. ${ }^{4}$ At the same time, the worldwide conversion from locally popular cigarette brands to the American style of blended tobacco cigarettes is increasing. For example, when worldwide cigarette demand was growing only $1 \%$ per year, the demand for American style products was projected to grow $3 \%$ annually. ${ }^{5}$

Before entrance of the transnational tobacco companies, consumer preferences tended to differ from country to country. For example, when PM first entered the European market in the $1950 \mathrm{~s},{ }^{6}$ dark tobacco was preferred in France, oriental tobacco in Greece, Virginia tobacco in the UK, and Maryland tobacco in Switzerland. Highly successful marketing strategies and distribution systems and, in some cases, cigarettes with a higher nicotine content resulted in American style blended tobacco cigarettes becoming the major choice in most markets, ${ }^{6-9}$ although around the world local preferences still exist. For example, cigarettes constructed primarily of Virginia tobacco hold $50 \%$ or more of the market share in several countries including Australia, Canada, India, Pakistan, and the UK. ${ }^{10}$

PM's flagship brand, Marlboro, became the world's best selling cigarette in 1972 and the best selling brand in the USA in $1975 .{ }^{11} 12$ In tandem with its worldwide recognition, Marlboro's share of the world market has risen every year since 1965. ${ }^{13}$ The Marlboro brand alone holds more than twice the world market share of any of its closest competitors. ${ }^{14}$ In addition, in 1983, PM became the largest US based international tobacco company. ${ }^{15}$ Philip Morris USA and Philip Morris International, Inc. constitute the largest international cigarette operation in the world, ${ }^{16}$ and PM's growing prominence in the global cigarette marketplace has attracted much interest from competitors.

Documents obtained as part the of the Minnesota tobacco trial settlement from Brown \& Williamson, a subsidiary of the transnational BAT, have focused on PM's continued success outside the USA. A Brown \& Williamson internal report, PM's global strategy: Marlboro product technology, ${ }^{17}$ states: "When Marlboro has been introduced into a market there is evidence that initial offerings may be closer to that market's traditional tastes. Over time, then, PM will alter the product and introduce product technology more consistent with an overall Marlboro sensory character." Reducing the number of Marlboro "recipes" clearly would allow the company to benefit from economies of scale in purchasing agreements and manufacturing costs, especially when domestic and export cigarette manufacture are combined.

If such claims by Brown \& Williamson are true, differences in the levels of smoke constituents between American western style cigarettes and non-US locally popular cigarettes may be important variables in the interpretation of the public health consequences of smoking in these countries. In this

Abbreviations: ANOVA, analysis of variance; BAT, British American Tobacco; CDC, Centers for Disease Control and Prevention; CFP, Cambridge filter pad; CO, carbon monoxide; FTC, Federal Trade Commission; GC, gas chromatography; GLM, general linear modeling; ISO, International Organization for Standardization; PM, Philip Morris; QC, quality control; TPM, total particulate matter; WHO, World Health Organization-AFRO, African Region; AMRO, American Region; EURO, European Region; EMRO, Eastern Mediterranean Region; SEARO, Southeast Asian Region; WPRO, Western Pacific Region 
study, we examined levels of nicotine, carbon monoxide (CO), and tar in mainstream smoke. All of these substances are associated with adverse health effects. For example, nicotine is the agent in tobacco that leads to addiction. ${ }^{18}$ Exposure to CO is associated with low birth weight infants, and it acts as an added stress in the precipitation of cardiovascular disease. ${ }^{19-21}$ Smoke particulate matter, minus water and nicotine, forms the portion of smoke known as tar, which contains the majority of the mutagenic and carcinogenic agents in tobacco smoke. ${ }^{22}$ However, not all tars are necessarily equal in terms of chemical composition. For example, altering the blend cigarette by increasing the amount of burley tobacco increases the nitrate content. Research of Hoffmann and colleagues has shown that the polyaromatic hydrocarbon content of the smoke can be reduced by an increase in nitrate content; unfortunately, the nitrosamine content increased proportionally with the nitrate levels. ${ }^{23}$ On a per cigarette basis, smoke from Virginia tobacco has a higher level of tar and total particular matter phenols and hydrogen cyanide than does smoke from burley tobacco. ${ }^{24}$ Therefore, differences in the tobacco blend composition influence the deliveries of smoke constituents.

To examine differences in tar, nicotine, and CO, we measured the mainstream smoke deliveries from 77 cigarette brands purchased in 35 countries. At a minimum, cigarettes were obtained and examined from at least three countries in each of the six World Health Organization regions: African Region (AFRO), American Region (AMRO), European Region (EURO), Eastern Mediterranean Region (EMRO), Southeast Asian Region (SEARO), and Western Pacific Region (WPRO).

\section{METHODS}

\section{Sample collection and storage}

Most of the cigarettes analysed during this study were obtained by WHO delegate members. We asked that three packs of full flavoured Marlboro cigarettes and three packs of the most popular local full flavoured brand be purchased from each participating country. The WHO Tobacco Free Initiative in Geneva (Switzerland) issued the request for the cigarettes (March 1999), served as a central collecting site, and forwarded the cigarettes to the Centers for Disease Control and Prevention (CDC). So that we also had cigarette samples from each of the six WHO regions, CDC personnel who were permanently stationed in Nigeria, Kenya, and South Africa also purchased cigarettes in these countries and forwarded them by overnight carrier or diplomatic pouch to the CDC for analysis. Brands were identified as common products through market data or, when market data were unavailable, by personal experience of local personnel in the country of interest. Upon arrival at the CDC, all cigarette packs were assigned an identification number and logged into a database developed using Paradox (Borland Inprise, Scotts Valley, California, USA). The samples were sealed in plastic bags and stored at $-70^{\circ} \mathrm{C}$ in their original packaging until tested.

Initially, we received 187 different samples from WHO delegates located in five of the six WHO regions (AMRO, EMRO, EURO, SEARO, and WPRO). An additional five samples were obtained from CDC personnel in Africa (AFRO). Forty one per cent of the submitted samples corresponded to the requested sample collection protocol and were included for analysis. Because a minimum of 10 cigarettes were required for the tar, nicotine, and CO analysis, we included only brands in this study for which we received at least 25 cigarettes.

The place of manufacture of the cigarettes was determined by visually inspecting the packs. The Marlboro cigarettes manufactured in the USA were identified as having "Made in U.S.A." printed on the pack or box, and those manufactured elsewhere had "Made under the authority of Philip Morris Inc. by" or "Made in" printed in the pack or box. Likewise, we identified "low-yield cigarette" brands from label descriptors such as "super-mild," "extra-mild," and "lights" on the cigarette packs.

Thirty one of the brands analysed were Marlboro full flavoured, king sized cigarettes. Approximately half of these were manufactured in the USA for export. We also analysed three Marlboro Lights brands. Among the locally popular brands analysed, two were non-filtered cigarette brands, seven claimed to be low yield cigarette brands (for example, lights, super-mild, extra-mild), two were mentholated brands, and one was a brand of menthol herbal cigarettes. Three types of experimental reference cigarettes, Kentucky Reference 1R3F (smoke delivery: $15 \mathrm{mg}$ tar, $1.16 \mathrm{mg}$ nicotine), IR4F (9.2 mg tar, $0.8 \mathrm{mg}$ nicotine), and IR5F (1.62 mg tar, $0.16 \mathrm{mg}$ nicotine) were used in this study as quality control (QC) reference cigarettes to span the range of deliveries available from full flavoured to ultralight. These cigarettes were purchased from the University of Kentucky Tobacco and Health Research Institute. The reference cigarettes, upon delivery, were stored at $-70^{\circ} \mathrm{C}$, and removed as needed. The QC reference cigarettes were used to characterise the mean and the 95th and 99th confidence intervals determined for the analysis of nicotine, CO, water content, and total particulate matter (TPM).

\section{Materials}

(-)-Nicotine, > 99\%, was purchased from Fluka (Milwaukee, Wisconsin). Anethole was purchased from Aldrich Chemical Co (Milwaukee). Methanol, purge and trap grade, was purchased from Burdick \& Jackson Inc (Muskegon, Michagan). Organic pure water (type I) was prepared inhouse using a Solution 2000 water-purification system (Solution Consultants Inc, Jasper, Georgia). Isopropanol, $0.015 \%$ in $\mathrm{H}_{2} \mathrm{O}$, was purchased from Tedia Company Inc (Fairfield, Ohio). The gases for gas chromatographic (GC) analysis were obtained from Air Products and Chemicals, Inc (Atlanta, Georgia). All chemicals and solvents were used without further purification.

The solvent for extraction of water and nicotine from the Cambridge filter pad (CFP) was prepared by dissolving $200 \mu \mathrm{l}$ of anethole and $3 \mathrm{ml}$ of $\mathrm{MeOH}$ in $2000 \mathrm{ml}$ of isopropanol. A water stock solution was prepared by dissolving $200 \mu \mathrm{l}$ of water in $25 \mathrm{ml}$ of extraction solvent. Likewise, a nicotine stock solution was prepared by dissolving $100 \mu \mathrm{l}$ of nicotine in $25 \mathrm{ml}$ of extraction solvent. The nicotine and water stock solutions were diluted with the extraction solvent to create eight standard sets whose concentrations encompassed the entire linear range of the method (that is, nicotine: from ca $0.01 \mathrm{mg} / \mathrm{ml}$ to $0.4 \mathrm{mg} / \mathrm{ml}$, and $\mathrm{H}_{2} \mathrm{O}$ : from ca $0.05 \mathrm{mg} / \mathrm{ml}$ to $1.2 \mathrm{mg} / \mathrm{ml}$ ).

\section{Instrumentation and analysis}

The tar, nicotine, and CO yields in the mainstream smoke from the 77 cigarette samples were analysed for this study by an adaptation of the method proposed by Pillsbury ${ }^{25}$ and the method specified by the US Federal Trade Commission (FTC). ${ }^{26}$ Before smoking, the cigarettes and CFPs were conditioned at $24^{\circ} \mathrm{C}$ and $60 \%$ relative humidity for at least 24 hours. Five cigarettes were smoked per port onto a $44 \mathrm{~mm}$ CFP (Fidus Instrument Corporation, Richmond, Virginia) using an automated Filtrona 8-port smoking machine (Filtrona Instruments \& Automation Ltd., Milton Keynes, UK) equipped with a CO analyser. The cigarettes were smoked to a butt length of $23 \mathrm{~mm}$ or the length of the filter overwrap plus $3 \mathrm{~mm}$, whichever was longer. Filter ventilation holes, if present, were not blocked or obscured in any manner. 
The smoking machine was calibrated daily to take a puff of two second duration and $35 \mathrm{ml}$ volume every minute and to maintain an average (SD) airflow velocity over the cigarettes of $200(30) \mathrm{mm} / \mathrm{s}$. We measured the puff volume $(35.0$ $(0.1) \mathrm{ml}$ ) using a $50 \mathrm{ml}$ soap film glass burette (Filtrona Instruments Corp, Richmond, Virginia). The airflow velocity (200 (50) $\mathrm{mm} / \mathrm{s}$ at the individual ports) was measured using a Filtrona VMD100 velocity measurement digitiser (Filtrona Instruments \& Automation Ltd, Milton Keynes, UK) connected to a Schiltknecht ThermoAir2 thermoelectric anemometer equipped with an omnidirectional probe (Schiltknecht Messtechnick AG, Gossau, Switzerland). The temperature and relative humidity inside the smoking chamber, measured with a Dickson THDx temperature, humidity, and dew point recorder (Dickson Company, Addison, IL), were set to $24 \pm 1{ }^{\circ} \mathrm{C}$ and $60 \pm 2 \%$, respectively. The atmospheric pressure inside the smoking chamber was measured using an Oakton barograph (Cole-Parmer Instrument Company, Chicago, Illinois). On each run, we used one of the ports of the smoking machine to smoke five reference cigarettes characterised as indicated above under "quality control materials". The cigarettes were analysed in duplicate for a total of 10 cigarettes smoked per brand.

The gas phase portion of the cigarette mainstream smoke was collected in vapour phase collection bags, and the percentage by volume of $\mathrm{CO}(\% \mathrm{CO})$ was determined using a Filtrona ATCOM 302 non-dispersive IR analyser (Filtrona Instruments \& Automation Ltd., Milton Keynes, UK). We calibrated the $\mathrm{CO}$ meter before each $\mathrm{CO}$ determination using three standard CO gas concentrations (3\%, 5\%, and $8 \%)$. The amount of $\mathrm{CO}$ in $\mathrm{mg}$ per cigarette was calculated using the following equation:

$$
\text { mg CO/cigarette }=\frac{\% \mathrm{CO} \times \mathrm{V} \times \mathrm{N} \times \mathrm{P} \times 273 \times 28}{\mathrm{~S} \times 100 \times 760 \times(\mathrm{T}+273) \times 22.4}
$$

where $\mathrm{V}$ is the puff volume in $\mathrm{ml}, \mathrm{N}$ is the number of puffs (including clearing puffs), $\mathrm{P}$ is the ambient pressure in $\mathrm{mm} \mathrm{Hg}, \mathrm{S}$ is the number of cigarettes smoked, and $\mathrm{T}$ is the room temperature in ${ }^{\circ} \mathrm{C}$.

To determine the nicotine and water concentration, after smoking, each CFP was placed in a $60 \mathrm{ml}$ desiccated serum bottle, and $20 \mathrm{ml}$ of extraction solvent was added. Then the bottles, capped with a rubber stopper and wrapped with parafilm, were shaken on a constant rate platform shaker for 30 minutes. Likewise, we prepared two or three blank samples per day by placing a conditioned CFP into a $60 \mathrm{ml}$ desiccated serum bottle and treating them as samples. After extracting the CFPs (including the blanks), we transferred an aliquot of the extract into an autosampler vial. Because of the presence of water vapour in the air, a backup vial was prepared for each sample in case a second water determination was needed. Backup samples were wrapped with parafilm and stored at $5^{\circ} \mathrm{C}$.

We analysed water on either a Hewlett Packard Model 5890 or 6890 gas chromatograph equipped with a thermal conductivity detector and an HP-Plot Q (Hewlett Packard, San Jose, California) capillary column $(15 \mathrm{~m} \times 0.32 \mathrm{~mm}$ inner diameter (id), $20 \mu \mathrm{m}$ film thickness). The helium flow rate was maintained at $1.7 \mathrm{ml} / \mathrm{min}$. Automatic injections $(2 \mu \mathrm{l})$ were made in the split mode with a split ratio of 40 to 1. The following temperature programme was used with the gas chromatograph: initial temperature $190^{\circ} \mathrm{C}$, hold for $2 \mathrm{~min}$, ramp at $40^{\circ} \mathrm{C} / \mathrm{min}$ to $230^{\circ} \mathrm{C}$, hold at final temperature for $7 \mathrm{~min}$. The GC injection port was held at $230^{\circ} \mathrm{C}$.

Nicotine was analysed using a Hewlett Packard Model 6890 gas chromatograph equipped with a flame ionisation detector. The 6890 gas chromatograph was equipped with an HP-Ultra 2 cross-linked 5\% phenyl-methyl silicone capillary column (25 $\mathrm{m} \times 0.32 \mathrm{~mm}$ id, $0.52 \mu \mathrm{m}$ film thickness $)$ (Hewlett Packard, San Jose). The helium flow rate was maintained at $1.7 \mathrm{ml} / \mathrm{min}$. Automatic injections $(2 \mu \mathrm{l})$ were made in the split mode with a split ratio of 40 to 1 . The following temperature programme was used with the gas chromatograph: initial temperature $190^{\circ} \mathrm{C}$, hold for $3 \mathrm{~min}$, ramp at $40^{\circ} \mathrm{C} / \mathrm{min}$ to $230^{\circ} \mathrm{C}$, hold at final temperature for 6 min.

The amounts of nicotine and water in cigarette smoke were determined quantitatively. Automated processing, which uses an automatic peak integration routine, was performed on the gas chromatographs. This routine calculates peak areas and retention times of the analytes of interest and writes this information to a quantitation file. All chromatograms were visually inspected to ensure that good integration limits were obtained. If necessary, the peak areas were manually integrated. The quantitation files for nicotine and water were converted to ASCII text files, then electronically transferred into a database that we developed using R-Base 4.5+ (Microrim Inc, Redmond, Washington) for storage, retrieval, and analysis of the data.

Nicotine and water were quantified by determining the relative response factors from the integrated peak areas of nicotine and water with respect to the peak areas of anethole and methanol. We determined the nicotine and water amounts using calibration curves of the nicotine and water concentration $(\mathrm{mg} / \mathrm{ml})$ versus the response factor. A linear regression analysis of the calibration curve provided the slopes and intercepts from which the nicotine and water amounts of unknown samples could be calculated. At least four repeat determinations were performed for each point on the calibration curve. The water content of the blank samples was determined daily from the calibration curve for water after the average water response factor from the blanks was subtracted from the water relative response factors of all sample runs from that day.

The TPM was obtained by calculating the weight difference in the CFP before and after the smoking process divided by the number of cigarettes smoked. The CFPs were weighed on a Sartorius MC210S analytical balance (Sartorius AG, Goettingen, Germany) interfaced to a computer used to collect and display the weight data onto a Software Wedge spreadsheet program (TAL Technologies Inc, Philadelphia, Pennsylvania). The tar content was calculated by subtracting the water and nicotine content from the TPM. Results are reported as mg of nicotine, $\mathrm{CO}$, or tar per cigarette $(\mathrm{mg} / \mathrm{cig})$. The statistical analyses including QC evaluations and analysis of variance (ANOVA) were performed with SAS statistical software (SAS Institute, Inc, Cary, North Carolina). A probability value of $\mathrm{p}<0.05$ was considered significant.

The amount of filter ventilation for each of the 77 cigarette samples was determined using a Filtrona QTM5 (Cerulean, Richmond, Virginia) filter ventilation measurement apparatus. The average and standard deviation values for the filter ventilation levels of cigarettes from each brand were obtained by measuring a minimum of five unconditioned cigarettes from each pack. Other physical parameters, including cigarette length, circumference, filter length, and filter material, were obtained from physical measurements and inspection on dissected cigarettes.

\section{RESULTS}

Selected physical characteristics including overall cigarette length, filter length, circumference, weight, and amount of filter ventilation for the cigarette sample analysed were measured for each cigarette sample. Although the request for cigarettes samples specified purchase of full flavoured brands, we also received several low delivery, mentholated, and unfiltered brands. For this report all cigarettes with a 
filter ventilation of less than $25 \%$, as measured by the QTM5, were considered full flavoured. The majority of the cigarette samples analysed were filtered (97\%), king sized, corresponding to approximately $85 \mathrm{~mm}$ in length $(95 \%)$, and nonmentholated (97\%). Two brands were unfiltered, but the majority of cigarettes contained a cellulose acetate filtered tip with an average length of $20 \mathrm{~mm}$. Only three brands, Derby, Klublowe, and Khukuri, had significantly shorter filter lengths of 14,12 , and $12 \mathrm{~mm}$, respectively. The cigarette rod circumference for all samples was relatively uniform, with an average (SD) of $24.2(0.4) \mathrm{mm}$.

We found no significant differences in the average cigarette weights among the filtered, full flavoured, non-mentholated cigarette brands. The average weights for full flavoured Marlboro manufactured in the USA, Marlboro manufactured outside the USA, and the full flavoured locally popular brands were $0.93 \mathrm{~g}, 0.93 \mathrm{~g}$, and $0.94 \mathrm{~g}$, respectively. Locally popular light cigarettes, on average, weighed less (0.79 g) than the full flavoured brands. The three Marlboro Lights brands, submitted from India, Lao People's Democratic Republic, and Vietnam, had an average weight of $0.94 \mathrm{~g}$. The average weight for the mentholated brands $(n=3)$ was $0.87 \mathrm{~g}$. In general, most of the cigarettes had similar physical characteristics.

The mean tar, nicotine, and CO smoke yields for all brands ranged from $6.8-21.6 \mathrm{mg}$ tar/cig, 0.50-1.63 mg nicotine/cig, and 5.9-17.4 mg CO/cig (table 1 ) (to view table 1 go to http// www.tobaccocontrol.com/supplemental). The amount of filter ventilation varied from less than $1 \%$ to $37 \%$. The percentage of filter ventilation measured in Marlboro cigarettes manufactured either in the USA or abroad ranged from $8.5-22.5 \%$ and from $0.8-24.8 \%$, respectively. Analysis of data for tar, nicotine, and CO levels measured in smoke from full flavoured Marlboro cigarettes manufactured in the USA for export compared with full flavour Marlboro cigarettes manufactured outside the USA were not statistically different (fig 1). The average filter ventilation percentage for Marlboro cigarettes made in the USA for export $(\mathrm{n}=17)$ was 14.3 $(4.4) \%$, while the ventilation for foreign made Marlboro cigarettes $(\mathrm{n}=14$ ) was $11.9(6.4) \%$; this calculated difference was not significant $(\mathrm{p}>0.05)$. For the three Marlboro Lights brands measured, the mean tar, nicotine, and CO smoke yields ranged from 7.4-10.3 mg tar/cigarette, 0.57$0.69 \mathrm{mg}$ nicotine/cigarette, and $8.7-11.0 \mathrm{mg} \mathrm{CO}$ /cigarette. As expected, the standardised cigarette smoking machine values for the Marlboro Lights cigarettes are typically lower than for the corresponding Marlboro full-flavoured brands purchased

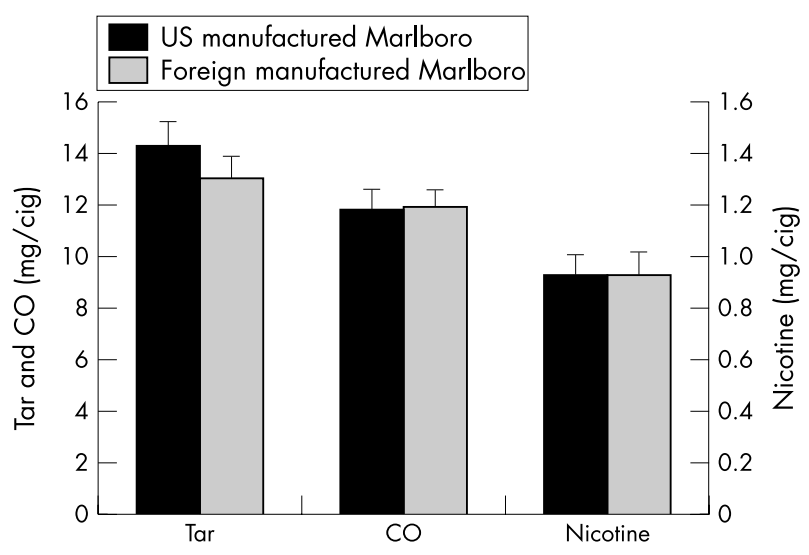

Figure 1 Comparison of measured tar, carbon monoxide (CO), and nicotine levels between Marlboro cigarettes manufactured in the USA to those manufactured outside the USA. in the same country. The percentage of filter ventilation for the Marlboro Lights brands ranged from 15.7-27.3\%.

Comparisons of the average smoke deliveries between the full flavoured Marlboro and the full flavoured locally popular cigarettes are shown in table 2. In several instances, no external information was available about smoke deliveries from the locally popular brands; therefore, we categorised brands with less than $25 \%$ filter ventilation as full flavoured. The average smoke deliveries of tar, nicotine, and CO appeared to be slightly higher for the full flavoured locally popular brands than the full flavoured Marlboro cigarettes, but the differences were not significant. The average amount of filter ventilation for the locally popular brands (6.8 (7.5)\%) was lower than that measured for the Marlboro cigarettes (13.2 (5.3)\%). The per cent relative standard deviation (RSD) for the tar, nicotine, $\mathrm{CO}$, and filter ventilation measurements reported here were $11.7 \%, 16.4 \%, 16.3 \%$, and $41.1 \%$, respectively, for the full flavoured Marlboro brands ( $\mathrm{n}=31$ ); and $28.90 \%, 25.1 \%, 23.4 \%$, and $115.5 \%$, respectively, for the locally popular bands analysed $(n=42)$. Nearly all (94\%) of the Marlboro cigarettes had filter ventilation holes, compared with approximately one third (34\%) of the locally popular brands. The calculated RSDs for tar, nicotine, and CO deliveries did not seem to reflect the same degree of variation in ventilation levels. Apparently factors other than ventilation can play significant roles in establishing acceptable consumer smoke deliveries.

Visual inspection indicated that most of the cigarette's filters were standard cellulose acetate. This included all of the Marlboro brands, except for two brands purchased in Tonga and Japan, which had filter tips made from a non-cellulose acetate material, possibly paper or polyester, and from a combination of charcoal and cellulose acetate, respectively. Filter tops of most of the locally popular brands were made of cellulose acetate; three of them (Broadway, Cleopatra, and A [red top hard pack]) contained a non-cellulose acetate material; these filter materials are unknown to us.

\section{DISCUSSION}

On the basis of FTC smoking parameters the Marlboro cigarettes purchased in different locales, on average, had relatively similar smoke deliveries of tar, nicotine, and CO, but there were some interesting exceptions. Some of the Marlboro brands, including those from Japan, Myanmar, Lebanon, and the Solomon Islands, had filter ventilation levels higher than $20 \%$, which is comparable with those measured for the Marlboro Lights brands. However, these more highly ventilated full flavoured Marlboro brands had tar, nicotine, and CO smoke yields similar to those from some of the less ventilated $(<10 \%)$ full flavoured Marlboro brands purchased in other areas. This supports the conclusion that factors other than filter ventilation-that is, blend composition, additives, paper porosity, or filter efficiency-may influence the smoke composition from a transnational brand.

Data on the smoke deliveries of the locally popular brands also showed interesting trends. One brand from the Philippines, Edes Herbal Menthol, did not contain detectable

Table 2 Averaged mean (SD) values for tar, nicotine, carbon monoxide (CO), and filter ventilation for locally popular and Marlboro brands

\begin{tabular}{lllll}
\hline Style & $\begin{array}{l}\text { Tar } \\
(\mathbf{m g} / \mathbf{c i g})\end{array}$ & $\begin{array}{l}\text { Nicotine } \\
(\mathbf{m g} / \mathbf{c i g})\end{array}$ & $\begin{array}{l}\text { co } \\
(\mathbf{m g} / \mathbf{c i g})\end{array}$ & $\%$ Ventilation \\
\hline $\begin{array}{l}\text { Locally popular } \\
\text { Marlboro }\end{array}$ & $14.4(3.8)$ & $0.94(0.23)$ & $11.9(2.5)$ & $6.8(7.5)$ \\
\hline
\end{tabular}


levels of nicotine. Despite the claim "non-nicotine, non-tar" printed on the pack, the mainstream smoke from the product contained $9.8 \mathrm{mg}$ tar/cigarette. Because tar is defined as the compounds other than nicotine and water present in the TPM from smoke, a "non-nicotine" cigarette does not mean a "non-tar" cigarette. Fuel other than tobacco in a burning cigarette can generate particulate matter, but the chemical composition of the tar may differ from a cigarette that contains tobacco. In addition, the smoke of this cigarette contained substantial amounts of CO (16.5 mg/cigarette). Although Edes Herbal brand did not contain measurable levels of nicotine, the remainder of the locally popular samples did.

Filter ventilation levels in the 77 cigarette samples we analysed ranged from $0-37 \%$ with $95 \%$ of the filtered brands having less than $25 \%$ filter ventilation. Therefore, to meaningfully compare tar, nicotine, and CO in mainstream smoke from the locally popular brands purchased in different WHO regions, the following discussion is limited to the filtered, nicotine containing, full flavoured cigarettes. All cigarettes with less than $25 \%$ filter ventilation were considered full flavoured brands. Therefore, the following analysis of mainstream smoke deliveries corresponds to the full flavoured locally popular brands. The herbal brand, unfiltered brands, all Marlboro samples, and light or low delivery brands with more than $25 \%$ filter ventilation (fig 2 ) were not included in the following analysis.

Average smoke deliveries of tar, nicotine, and $\mathrm{CO}$ as measured by the FTC methodology and filter ventilation levels differed among the regions (fig 2). The highest deliveries of tar are in the EMRO and SEARO regions, which also have correspondingly lower average filter ventilation levels. Kozlowski et $a^{27}$ reported the nicotine content in both the tobacco and mainstream smoke for cigarettes with a range of filter ventilation levels that were purchased in the USA, Canada, and the UK; most of the cigarettes sampled from these three countries were ventilated, and filter ventilation was the biggest predictor for smoke deliveries. We examined a limited number of cigarettes from numerous countries with emphasis on the smoke deliveries obtained from full flavoured cigarettes. In agreement with Kozlowski et al, ${ }^{27}$ our data show that filter ventilation has a direct, major influence on smoke deliveries from the brands purchased in multiple countries.
However, inspection of the smoke deliveries from the locally popular brands (fig 2) suggests that additional factors, perhaps related to either local consumer preferences or other regional differences, could influence cigarette design and smoke deliveries. As an example, compare the WPRO region, which has an average tar delivery approximately equal to EMRO and SEARO, but has an average per cent ventilation that is three times higher than these two regions. Also, the cigarettes from the AFRO region have an average tar delivery similar to those for the AMRO and EURO regions, but the average per cent ventilation is substantially lower than in cigarettes from these other regions. Such regional differences could be related to differences in the tobacco blends and tobacco types used. Eight of the Western Pacific and Southeast Asian brands were identified on the pack label as using Virginia or flue-cured tobacco. These brands had higher average tar (19.1 (3.01) mg tar/cigarette) and nicotine (1.39 (0.48) mg nicotine/cigarette) smoke deliveries, but these increased yields could be attributed to the lack of filter ventilation holes in all eight brands. Although other local tobacco blend preferences exist, such as dark air-cured burley types of tobacco smoked in areas of Europe and South America, ${ }^{28}$ information about the type of tobacco used for the remaining locally popular brands was not available from the cigarette packs. An analysis of Taiwanese cigarettes by Lee et $a l^{29}$ purchased in 1997 and smoked according to International Organization for Standardization (ISO) smoking conditions revealed that locally produced cigarettes, on average, contained more tar and nicotine than imported transnational brands. Alternatively, the regional differences may also be partially attributed to other effects such as undersampling of certain WHO regions.

To provide a more quantitative comparison of the influence of purchase location and filter ventilation on the measured smoke deliveries, ANOVA using the general linear modelling (GLM) approach was applied to the smoke deliveries of the locally popular brands. The tar, nicotine, and CO levels were analysed to determine whether WHO region (location), ventilation, or an interaction between the location and ventilation had a significant predictive value. The average tar value was strongly correlated with ventilation $(\mathrm{p}=0.004)$, in good agreement with the work of Kozlowski, ${ }^{27}$ but not with location $(p>0.05)$. Interestingly, the nicotine levels were correlated with the location

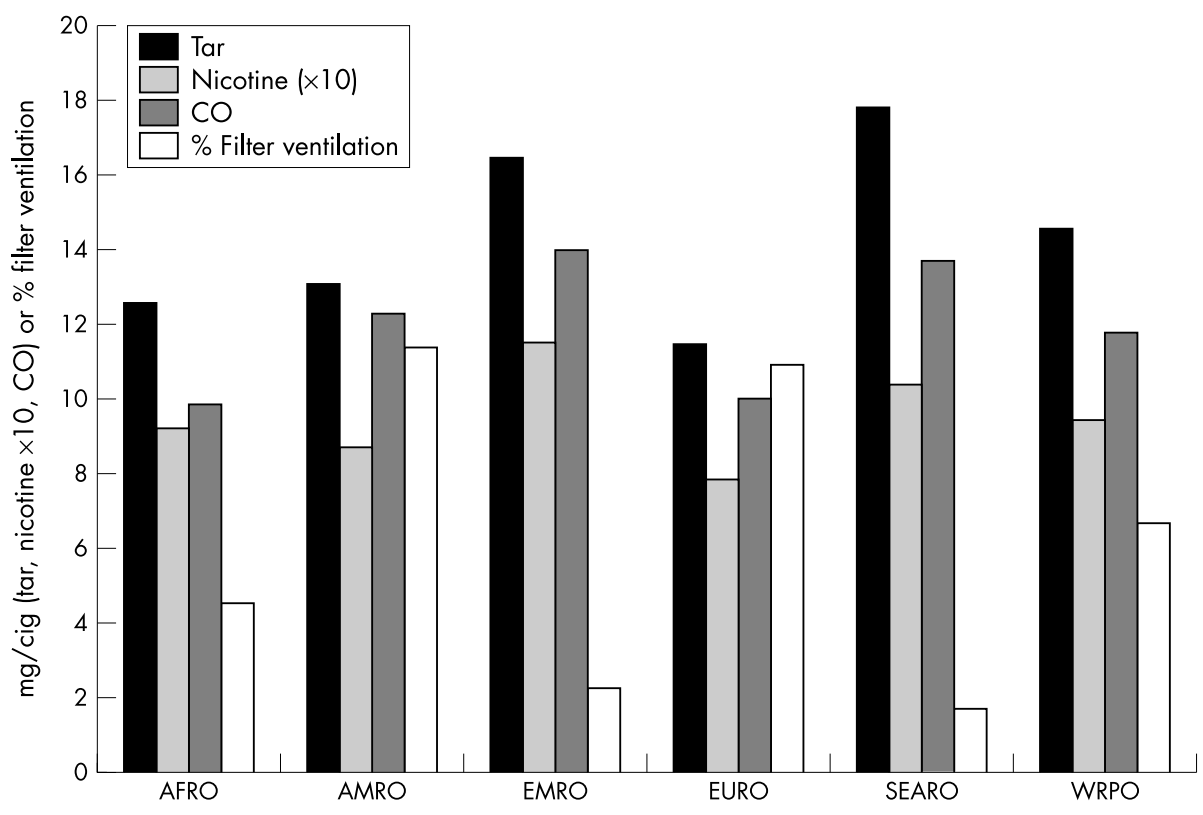

Figure 2 Average values of tar, nicotine, carbon monoxide (CO), and filter ventilation levels measured in cigarettes from different World Health Organization regions. See footnote on first page for explanation of $\mathrm{WHO}$ regions. 


\section{What this paper adds}

Cigarette smoking remains a global source of major health problems and is the leading cause of preventable diseases such as lung cancer. The goal of this work was to examine worldwide mainstream smoke deliveries from locally popular cigarettes and a widely available transnational brand. We analysed smoke deliveries of tar, nicotine, and carbon monoxide in mainstream smoke from 77 cigarette brands purchased in 35 countries. The smoke deliveries of the transnational brand was remarkably consistent in all countries. However, among the locally produced brands smoke deliveries appeared to differ by region. On the basis of machine smoking data, the smoke deliveries of locally popular brands from eastern Europe and the southeastern Asia tended to have higher deliveries than did those from western Europe, Africa, and the Americas.

$(p=0.0012)$, filter ventilation $(p=0.0008)$, and their interactive combination $(p=0.0015)$. These data suggest that both location and filter ventilation have predictive values and are important, but the effect of filter ventilation on nicotine delivery is not the same in each region. The CO levels were significantly correlated with both location $(p=0.0136)$ and ventilation $(p=0.0008)$. Although the amount of filter ventilation is obviously the dominant effect, regional differences also appear to contribute a lesser, but significant, role in the potential range of commercially acceptable levels of smoke deliveries of tar, nicotine, and CO.

\section{Conclusion}

Our findings indicate that differences in tar, nicotine, and CO yields in smoke, and the level of filter tip ventilation between full flavoured Marlboro cigarettes manufactured locally or imported from the USA are not significant. Although slightly higher average smoke deliveries of tar, nicotine, and CO were observed for locally popular full flavoured cigarettes than for the full flavoured Marlboro cigarettes, the measured differences in smoke deliveries from these samples also were not found to be significant at the $95 \%$ confidence interval. Statistical analysis of the smoke deliveries of tar, nicotine, and $\mathrm{CO}$ from the locally popular brands on a regional basis did reveal significant differences related primarily to the amount of filter ventilation and secondarily to the region where the cigarettes were purchased. The findings on tar, nicotine, and CO deliveries are based on standardised machine smoking conditions. Filter ventilation had the largest overall influence on mainstream smoke deliveries. However, an important limitation of this study is that people do not smoke cigarettes as machines smoke them. Therefore, regional or cultural cigarette smoking practices, along with differences in tobacco variety, blend, and quality, may have a large influence on the consumption and resulting dosage levels of tar, nicotine, and CO. The measured mainstream smoke deliveries do provide an interesting comparison between many different cigarettes purchased in diverse locations. On the basis of the analysis of machine generated smoking data, smokers in EMRO and SEARO appear to have access to higher delivery cigarettes after removal of the filter ventilation confounder. This work did not specifically address an explanation for the basis of any regional differences. However, the nature of such differences in smoke deliveries can be attributed to one or more factors including local consumer preferences, public awareness of tobacco related health risks with subsequent desire for cigarettes with lower smoke deliveries, use of certain tobacco blend components, construction technique, or other manufacturing differences.
Mainstream smoke, regardless of type or style of cigarette, contains numerous toxic chemical constituents, ${ }^{22}$ including several known classes of carcinogens such as arenes, heavy metals, aminobiphenyls, polyaromatic hydrocarbons, and tobacco specific nitrosoamines. ${ }^{30}$ Many smokers switch to lower yield cigarettes out of concern for their health. However, design elasticity and smoker compensation result in higher yields of nicotine and other smoke constituents, suggesting that switching from higher to lower yield cigarettes is not likely to reduce disease risk. ${ }^{31}$ In fact, there are some suggestions that lower delivery cigarettes may be as harmful as full flavoured cigarettes. ${ }^{31}$ Therefore, the only safe and effective way to minimise smoking related health risks is to not smoke.

\section{ACKNOWLEDGEMENTS}

Technical assistance provided by Yamaira Liboy Casiano and Lisa Brown Guidry is gratefully appreciated. We also acknowledge financial support for this study from the CDC's National Center for Chronic Disease Prevention and Health Promotion and Office of Smoking and Health.

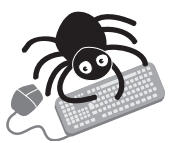

To view table 1 visit the Tobacco Control website$\mathrm{http} / / \mathrm{www}$.tobaccocontrol.com/supplemental

\section{Authors' affiliations}

A M Calafat, G M Polzin, D L Ashley, C H Watson, National Center for Environmental Health, Centers for Disease Control and Prevention, Atlanta, Georgia, USA

P Richter, Office on Smoking and Health, NCCDPHP, Centers for Disease Control and Prevention, Atlanta, Georgia, USA

J Saylor, Texas A\&M University, College Station, Texas, USA

\section{REFERENCES}

1 Centers for Disease Control and Prevention, Cigarette smoking among adultsUnited States, 1998. MMWR Morb Mortal Wkly Rep 2000;49:881-4.

2 Corrao MA, Guindon GE, Sharma N, et al. Tobacco control country profiles. Atlanta, Georgia: American Cancer Society, 2000.

3 World Bank. Curbing the epidemic: governments and the economics of tobacco control. Development in Practice Series. Washington DC: The World Bank, 1999.

4 Amos A. Cigarette advertising and marketing strategies. Tobacco Control 1992;1:3-4.

5 Tobacco International. Global tobacco: building on the past to compete in the future. The Philip Morris Issue. Tobacco International October 1996:41-2.

6 Anon. Tobacco Reporter, Philip Morris Europe. Legendary marketing skills. Tobacco Reporter. September 1989:22-4.

7 Hwang SL. Sucked in: How Philip Morris got Turkey Hooked on American Tobacco. The Wall Street Journal September 11, 1998:A1

8 John GA. Global strategy, local tactics put PM products on top in EEC Tobacco International July 15, 1989:31-2.

9 Anon. Tobacco International, Philip Morris European Union. Dominating the market with Marlboro. Tobacco International October 1996:47-8.

10 The Maxwell Report. 1999 International Tobacco Report - Part One. The Maxwell Report. April 28, 2000. Maxwell. 2000b. 1999 International Tobacco Report - Part Two. The Maxwell Report. July 28, 2000.

11 Philip Morris. Philip Morris History. Bates No. 2023037424-2023037437. CDC Tobacco Industry Documents. Minnesota Select Set. Website available at: <http://outside.cdc.gov:8080/BASIS/ncctld/web/mnimages/ DDW?W = DETAILSID = 14174>

12 Anon. Tobacco International, Regal Marlboro continues to reign supreme. Tobacco International October 1996:43-7.

13 Zimmerman C. Profile: Philip Morris. Capitalizing on the new world order. Tobacco Reporter September 1991:24-30.

14 Anon. Tobacco International, Philip Morris: Introduction. Leader of the Packs. Tobacco International May 15, 1993:26-30.

15 Philip Morris, 2001. Philip Morris International. History. Website available at: <http://www.pmintl.com/about_us/history.html >.

16 World Tobacco File. Philip Morris. Volume 2. Market Tracking International Ltd. London, 1996.

17 Gordon DL. 1992. PM's Global Strategy: Marlboro Product Technology. Brown \& Williamson Tobacco Corporation. R\&D-BOT3-92. October 23, 1992. Bates No. 510311835 - 510311848 . Website available at: <http:// outside.cdc.gov:8080/BASIS/ncctld/web/mnimages/ EDW?W $=$ DETAILSID $=3055$

18 US Department of Health and Human Services. The health consequences of smoking: nicotine addiction. A report of the Surgeon General, 1988. 
Rockville, Maryland: Public Health Service, Centers for Disease Control, Office on Smoking and Health, 1988. (DHHS Publication No (CDC) 88-8406.)

19 Dempsey DA, Benowitz NL. Risks and benefits of nicotine to aid smoking cessation in pregnancy. Drug Safety 1983;24:277-322.

20 US Department of Health and Human Services. The health consequences of smoking: cardiovascular disease. A report of the Surgeon General, 1983. Rockville, Maryland: Public Health Service, Office on Smoking and Health, 1983. (DHHS Publication No (PHS) 84-50204.)

21 Secker-Walker RH, Vacek PM, Flynn BS, Mead PB. Smoking in pregnancy, exhaled carbon monoxide, and birth weight. Obstet Gynecol 1997:89:648-53.

22 International Agency for Research on Cancer (IARC). IARC monographs on the evaluation of the carcinogenic risk of chemicals to humans. Tobacco smoking. Lyon, France: IARC, 1986.

23 Adams JD, Lee SJ, Hoffmann D. Carcinogenic agents in cigarette smoke and the influence of nitrate on their formation. Carcinogenesis 1984;2:221-3.

24 Browne CL. The design of cigarettes, 3rd ed. Hoechst Celanese, 1990:1-118.

25 Pillsbury HC Jr. Review of the Federal Trade Commission method for

determining cigarette tar and nicotine yield. The FTC cigarette test method for determining tar, nicotine, and carbon monoxide yields of US cigarettes: report of the $\mathrm{NCl}$ Expert Committee. Bethesda, Maryland: National Institutes of Health, National Cancer Institute 1996. (NIH Publication No 96-4028.)
26 National Cancer Institute. The FTC cigarette test method for determining tar, nicotine, and carbon monoxide yields of US cigarettes: report of the $\mathrm{NCl}$ Expert Committee. Bethesda, Maryland: National Institutes of Health, National Cancer Institute 1996. (NIH Publication No 96-4028.)

27 Kozlowski LT, Mehta NY, Sweeney CT, et al. Filter ventilation and nicotine content of tobacco in cigarettes from Canada, the United Kingdom, and the United States. Tobacco Control 1998;7:369-75.

28 Hoffman D, Hoffman I. The changing cigarette. J Toxicol Environ Health 1997;50:307-64.

29 Lee WC, Li TL, Cheng WJ, et al. Survey of nicotine and tar yields of domestic and imported cigarettes. J Food Drug Anals 1998:691-701.

30 US Department of Health and Human Services. Reducing the health consequences of smoking: 25 years of progress. A report of the Surgeon General, 1989. Rockville, Maryland: Public Health Service, Centers for Disease Control, Office on Smoking and Health, 1989. (DHHS Publication No (CDC) 89-8411).

31 National Cancer Institute. Risks associated with smoking cigarettes with low machine-measured yields of tar and nicotine. Smoking and Tobacco Control Monograph No.13, Bethesda, Maryland: US Department of Health and Human Services, National Institutes of Health, National Cancer Institute, 2001. (NIH Publication No.02-5074.)

\section{The lighter side}

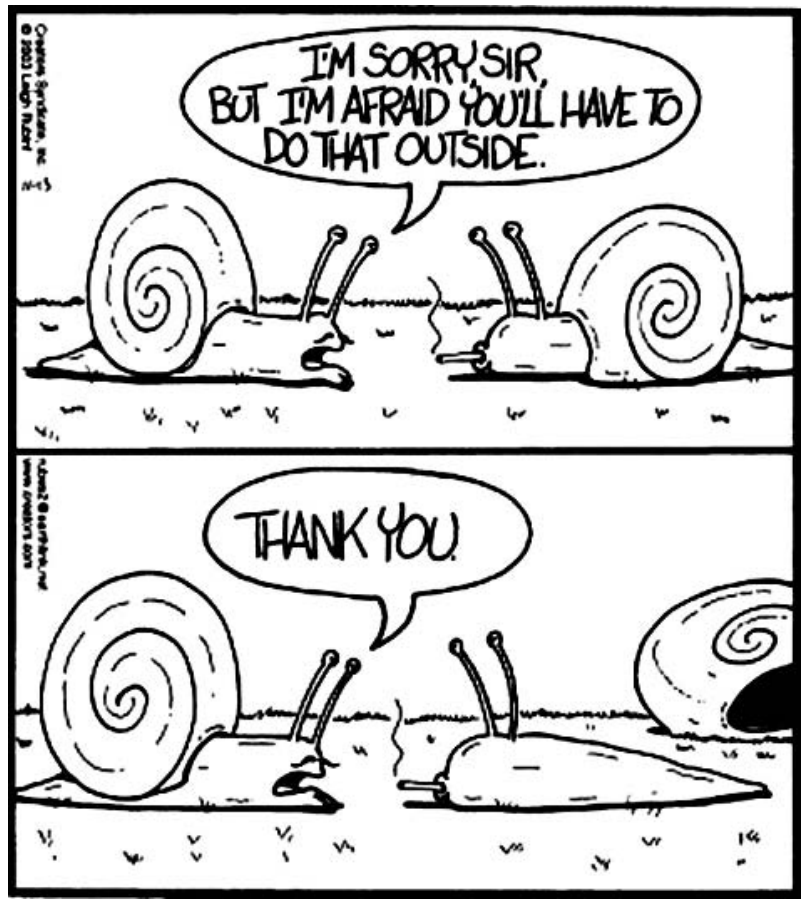

(c) Rubes, by Leigh Rubin, Creators Syndicate. 